\title{
Trends and in- hospital mortality of Acute Coronary Syndrome at Shahid Gangalal National Heart Centre, Kathmandu, Nepal during 2001-2012
}

Chandra Mani Adhikari," Deewakar Sharma, Rabi Malla, Sujeeb Rajbhandari, Roshan Raut, Sajan Baidya, Murari Dhungana, Dipanker Prajapati, Yadav Bhatta, Man Bahadur KC

Department of Cardiology, Shahid Gangalal National Heart Centre, Bansbari, Kathmandu, Nepal.

\author{
Accepted on \\ January $16^{\text {th }}, 2014$ \\ DOI Name \\ http://dx.doi.org/10.3126/jaim.v3i1.10698

\section{Keywords} \\ Acute Coronary Syndrome, ST elevation Myocardial \\ Infarction, In-hospital mortality \\ Citation \\ Chandra Mani Adhikari, Deewakar Sharma, Rabi \\ Malla, Sujeeb Rajbhandari, Roshan Raut, Sajan \\ Baidya, Murari Dhungana, Dipanker Prajapati, \\ Yadav Bhatta, Man Bahadur KC. Trends and in- \\ hospital mortality of Acute Coronary Syndrome \\ at Shahid Gangalal National Heart Centre, \\ Kathmandu, Nepal during 2001-2012. Journal of \\ Advances in Internal Medicine 2014;03(01):23-26.
}

\begin{abstract}
Background and aims: Acute coronary syndrome (ACS), which comprises acute ST-segment elevation myocardial infarction, non-ST segment elevation myocardial infarction and unstable angina is a major health problem and represents a large number of hospitalizations annually worldwide. We aim to describe pattern of the ACS admission and in-hospital mortality at tertiary national heart centre of the country.

Methods: A hospital database was used to analyze all 7424 patients admitted in coronary care unit of the centre for ACS from September 2001 till December 2012. We evaluated trend of ACS admission and in-hospital mortality.

Results: Five thousand three hundred ninety one (72.6\%) were male and two thousand thirty three $(27.4 \%)$ were female. Patient of 21 years to 98 years were admitted for ACS .Four thousand five hundred and ninety nine(61.9\%) patient were admitted due to ST elevation myocardial infarction, whereas one thousand nine hundred and thirteen (25.8\%) were admitted for Unstable angina and nine hundred twelve (12.3\%) were admitted for Non ST elevation myocardial infarction. In-hospital mortality was $5.74 \%$ for acute coronary syndrome. There was significant difference in in-hospital mortality between ST elevation myocardial infarction (7.76\%), Non ST segment elevation acute coronary syndrome (3.61\%) and Unstable Angina (1.88\%).There is a gradual increase in Primary Percutaneous Coronary intervention as a mode of reperfusion therapy whereas there is a decrease in the rate of thrombolysis.
\end{abstract}

Conclusion: Our study provides us some important information about the trend and in-hospital mortality rate in national heart centre. Though it is a single centre study can provide us the insight of the ACS outcome.

\section{INTRODUCTION}

Atherosclerotic cardiovascular disease, manifested mainly as acute coronary syndrome (ACS), ${ }^{1,2}$ is a major health problem and represents a large number of hospitalizations annually worldwide. ${ }^{3}$ ACS is not only a common cause of medical consultations and admissions at emergency departments, but also is a major cause of morbidity and mortality. ${ }^{4,5} \mathrm{It}$ now presents as a major burden on healthcare resources.
It comprises a group of entities including acute ST-segment elevation myocardial infarction (STEMI), non-ST segment elevation myocardial infarction (NSTEMI), and unstable angina is a result of atherosclerotic and thrombotic processes.

\footnotetext{
* Corresponding author

Chandra Mani Adhikari

Shahid Gangalal National Heart Centre,

Bansbari,Kathmandu,Nepal

Email: topjhap@hotmail.com
} 
There are limited data on the nature and distribution of ACS in Nepal. The present study was conducted to describe pattern of the ACS admission and in-hospital mortality at tertiary national heart centre of the country.

\section{METHODS}

It was a single centre retrospective study conducted at Shahid Gangalal National heart Centre (SGNHC), Kathmandu, Nepal. A hospital database was used to analyze all 7424 patients admitted in coronary care unit (CCU) of the centre for ACS from September 2001 till December 2012. Performa was designed to collect patient information which included; age, gender, ACS diagnosis, types of reperfusion therapy used were also collected. Patients included were males and females of all age groups. The initial diagnosis was made by the attending cardiologist, based on clinical presentation, initial electrocardiographic pattern, and markers of myocardial necrosis acquired at least 6 hours after the symptom onset. We evaluated trend of ACS admission and in-hospital mortality. The study protocol was approved by the Ethics Committee of SGNHC. All the variables were entered into the Statistical Package for Social Sciences software, version 14 (SPSS Inc) for data analysis.

\section{RESULTS}

The study included all (7424) ACS patients admitted to CCU of SGNHC from September 2001 till December 2012. Five thousand three hundred ninety one $(72.6 \%)$ were male and two thousand thirty three $(27.4 \%)$ were female. Patient of 21 years to 98 years were admitted for ACS. Four thousand five hundred and ninety nine (61.9\%) patients were admitted due to STEMI, whereas one thousand nine hundred and thirteen (25.8\%) were admitted for Unstable angina and nine hundred twelve (12.3\%) were admitted for NSTEMI. STEMI was the most common form of ACS followed by unstable angina as shown in table 1.

Table 1. Distribution of ACS

\begin{tabular}{|c|c|c|}
\hline ACS & No & $\%$ \\
\hline Unstable Angina & 1913 & 25.8 \\
\hline NSTEMI & 912 & 12.3 \\
\hline STEMI & 4599 & 61.9 \\
\hline
\end{tabular}

In all forms of ACS, male predominate could be seen as shown in Table 2.

Table 2. Distribution of ACS among Male and Female

\begin{tabular}{llccc}
\hline & \multicolumn{2}{c}{ Male } & \multicolumn{2}{c}{ Female } \\
& N & (\%) & N & (\%) \\
\hline Unstable Angina & 1250 & $(65.4)$ & 663 & $(34.6)$ \\
NSTEMI & 650 & $(71.2)$ & 262 & $(28.8)$ \\
STEMI & 3491 & $(75.9)$ & 1108 & $(24.1)$ \\
\hline
\end{tabular}

Among STEMI, Inferior wall Myocardial infarction was the most common reason for admission followed by anterior wall myocardial infarction. Table 3

Table 3 Distribution of STEMI

\begin{tabular}{lcc}
\hline \multicolumn{1}{c}{ STEMI } & No & $\%$ \\
\hline Inferior & 1655 & 35.9 \\
Anterior & 1096 & 23.8 \\
Extensive Anterior & 634 & 13.7 \\
Antero-Septal & 483 & 10.5 \\
Infero-posterior & 221 & 4.8 \\
Inferior with RV Infraction & 160 & 3.5 \\
Infero lateral & 96 & 2.1 \\
Others & 254 & 5.5 \\
\hline
\end{tabular}

Among the 4599 STEMI patients, only $24.8 \%$ patients underwent reperfusion therapy. The commonly used reperfusion therapy was thrombolytic therapy. It was the mode of reperfusion therapy in $18.3 \%$ patients among STEMI patient. Only $6.4 \%$ patients underwent primary percutaneous coronary intervention (PPCl). Thrombolytic therapy constitute $74.1 \%$ of the mode of reperfusion therapy where as $\mathrm{PPCl}$ constitute only $25.9 \%$.

In-hospital mortality was $5.74 \%$ for ACS. STEMI (7.76\%) had the highest in hospital mortality rate followed by NSTEMI (3.61\%) and Unstable Angina (1.88\%).Table 4 shows the difference in the in-hospital mortality rate among male, female and overall.

Table 4 Mortality rate among Male, Female and overall

\begin{tabular}{lcccccc}
\hline & Male & $\%$ & Female & $\%$ & Overall & $\%$ \\
\hline UA & $23 / 1250$ & 1.84 & $13 / 663$ & 1.96 & $36 / 1913$ & 1.88 \\
NSTEMI & $19 / 650$ & 2.92 & $14 / 262$ & 5.34 & $33 / 912$ & 3.61 \\
STEMI & $237 / 3491$ & 6.78 & $120 / 1108$ & 10.83 & $357 / 4599$ & 7.76 \\
ACS & $279 / 5391$ & 5.17 & $147 / 2033$ & 7.23 & $426 / 7424$ & 5.74 \\
\hline
\end{tabular}

\section{DISCUSSION}

In real-life, there are substantial differences between ACS patient population and clinical trial patient population with significant heterogeneity in studies conducted in clinical practice. ${ }^{6}{ }^{7}$ In this study we provide a pattern of ACS admission and in-hospital mortality in our population of ACS patients. As our centre being the tertiary referral centre of the country, can in some extent reflect the pattern of ACS admission in the country and can be an important observation. Our study can provide a reliable contemporary picture of patients with ACS and can identify areas of possible improvement and to define strategies for optimal care delivery.

By contrast with data from developed countries, we recorded more cases of STEMI than NSTEMI and UA. The types of ACS in 
our study differed from those recorded in developed countries. About $60 \%$ of patients who we assessed had STEMI, whereas in reports from developed countries, including the European Heart Surveys fewer than $40 \%$ had STEMI. ${ }^{8,9,10,11}$

Timely administration of reperfusion therapy by primary angioplasty or thrombolysis is the recommended treatment for most patients with STEMI. ${ }^{12}{ }^{13}$ Reperfusion treatment was administered in hospital to $27.5 \%$ of patients with STEMI. Failure to reach the hospital within 12 hours is the primary reason for not instituting the thrombolytic therapy in STEMI.

The reperfusion rates observed in this study are very low to those reported in the most recent surveys which clearly demonstrate the existing difference in our study and the developed countries. In the Global Registry of Acute Coronary Events ( GRACE) registry, $47 \%$ of STEMI received thrombolytic treatment, and $18 \%$ primary $\mathrm{PCl}$ with an overall ratio similar to Euro Heart Survey ACS (2.6:1). However, huge differences were observed among different geographic areas, from a ratio of 1.6:1 in the USA to a ratio of 64:1 in the area Australia-New Zealand-Canada. ${ }^{12}$

\section{REFERENCES}

1 O'Kelly B, Massie B, Tubau J, et al. Coronary morbidity and mortality, pre-existing silent coronary artery disease, and mild hypertension. Ann Intern Med 1989;110:1017-26.

http://dx.doi.org/10.7326/0003-4819-110-12-1017

2. Bakhai A. The burden of coronary, cerebrovascular and peripheral arterial disease. Pharmacoeconomics 2004;22:11-8.

http://dx.doi.org/10.2165/00019053-200422004-00004

3. Murray CJ, Lopez AD. Mortality by cause for eight regions of the world: Global Burden of Disease Study. Lancet 1997; 349: 1269-76.

http://dx.doi.org/10.1016/S0140-6736(96)07493-4

4. Fox K AA, Goodman SG, Klein W, et al. Management of acute coronary syndromes. Variations in practice and outcome. Eur Heart J 2002; 23: 1177-1189.

http://dx.doi.org/10.1053/euhj.2001.3081

5. The GRACE Investigators. GRACE (Global Registry of Acute Coronary Events): a multinational registry of patients hospitalized with acute coronary syndromes. Am Heart J 2001; 141: 190-9.

http://dx.doi.org/10.1067/mhj.2001.112404

6. Caro JJ, Magliaccio-Walle K, for the CAPRA (CAPRIE Actual Practice Rates Analysis) Study Group. Generalizing the results of clinical trials to actual practice: the example
ACS in-hospital mortality of $5.74 \%$ was comparable to the $5.53 \%$ in the Brazilian registry. ${ }^{14}$ In-hospital mortality of STEMI patients $(7.76 \%)$ in our study is lower than that reported in the National Registry of Myocardial Infarction 3 study $(9 \%)^{15}$ and of Brazilain registry (8.10\%). ${ }^{14}$ Likewise, in-hospital mortality of NSTEMI in our study is $3.39 \%$ is much lower than the $7 \%{ }^{16}$ of Malaysian registry and $6.80 \%$ in Brazilian registry. ${ }^{14}$ When we compared in-hospital mortality $1.93 \%$ of Unstable Angina is lower than the Malaysian registry which has mortality of $3 \%{ }^{16}$

Single centre, retrospective study is some of the limitation of our study.

\section{CONCLUSION}

The present study provides a better picture of trends and in-hospital mortality in our centre. Since the present study includes tertiary cardiac care centre of Nepal, the in-hospital mortality cannot represent the whole country. This study finding also suggests that favorable outcomes, matching the international can be achieved in the management of ACS.

of clopidogrel therapy for the prevention of vascular events. Am J Med 1999; 107: 568-572.

http://dx.doi.org/10.1016/S0002-9343(99)00295-8

7. Steg PG, Goldeberg RJ, Gore JM, et al. Baseline characteristics, management practices, and in-hospital outcomes of patients hospitalized with acute coronary syndromes in the Global Registry of Acute Coronary Events (GRACE). Am J Cardiol 2002; 90: 358-363.

http://dx.doi.org/10.1016/S0002-9149(02)02489-X

8. Denis Xavier, Prem Pais, P J Devereaux et al;On behalf of the CREATE registry investigators. Treatment and outcomes of acute coronary syndromes in India (CREATE): a prospective analysis of registry data. Lancet 2008; 371:1435-42.

http://dx.doi.org/10.1016/S0140-6736(08)60623-6

9. Hasdai D, Behar S, Wallentin L, et al. A prospective survey of the characteristics, treatments and outcomes of patients with acute coronary syndromes in Europe and the Mediterranean basin; the Euro Heart Survey of Acute Coronary Syndromes (Euro Heart Survey ACS). Eur Heart J 2002; 23: 1190-201.

http://dx.doi.org/10.1053/euhj.2002.3193

10. Fox KA, Goodman SG, Klein W et al. Management of acute coronary syndromes. Variations in practice and outcome. Findings from the Global Registry of Acute Coronary Events (GRACE).Eur Heart J 2002; 23:1177-89.

http://dx.doi.org/10.1053/euhj.2001.3081 
11. Fox KA, Cokkinos DV, Deckers J et al. The ENACT study: a pan- European survey of acute coronary syndromes. European Network for Acute Coronary Treatment. Eur Heart J 2000; 21:1440-9.

http://dx.doi.org/10.1053/euhj.2000.2185

12. Ryan TJ, Antman EM, Brooks NH et al. Update 1999: ACC/ AHA guidelines for the management of patients with acute myocardial infarction. A report of the American College of Cardiology/American Heart Association Task Force on Practice Guidelines (Committee on Management of Acute Myocardial Infarction). J Am Coll Cardiol 1999; 34:890-911.

http://dx.doi.org/10.1016/S0735-1097(99)00351-4

13. Smith SC, Jr., Dove JT, Jacobs AK et al. ACC/AHA guidelines of percutaneous coronary interventions (revision of the 1993 PTCA guidelines) - executive summary. A report of the American College of Cardiology/American Heart Association Task Force on Practice Guidelines (committee to revise the 1993 guidelines for percutaneous transluminal coronary angioplasty). 2001.

14. Leopoldo Soares Piega1, Álvaro Avezum, Hélio Penna Guimarães et al. Acute Coronary Syndrome Behavior: Results of a Brazilian Registry. Arq Bras Cardiol. 2013; 100(6):502-10.

15. Rogers WJ, Canto JG, Lambrew CT, et al. Temporal trends in the treatment of over 1,5 million patients with myocardial infarction in the US from 1990 through 1999: the National Registry of Myocardial Infarction 1, 2 and 3. J Am Coll Cardiol 2000; 36: 2056-63.

http://dx.doi.org/10.1016/\$0735-1097(00)00996-7

16. S P Chin, S Jeyaindran, R Azhari, W A Wan Azman, et al. Acute Coronary Syndrome (ACS) Registry - Leading the Charge for National Cardiovascular Disease (NCVD) Database. Med J Malaysia 2008; Vol 63 Supplement C: 29-36. 